BULLETIN Bulletin hispanique

HISPANIQUE Université Michel de Montaigne Bordeaux

109-2 | 2007

La formation du Parnasse espagnol $\mathrm{XV}^{\mathrm{e}}-\mathrm{XVIII}{ }^{\mathrm{e}}$ siècle

\title{
Entre Mayans y Luzán
}

la necesidad de un Parnaso

\section{Françoise Étienvre}

\section{(2) OpenEdition}

\section{Journals}

Édition électronique

URL : http://journals.openedition.org/bulletinhispanique/352

DOI : 10.4000/bulletinhispanique.352

ISSN : 1775-3821

Éditeur

Presses universitaires de Bordeaux

Édition imprimée

Date de publication : 1 décembre 2007

Pagination : 685-708

ISBN : 978-2-85276-096-7

ISSN : 0007-4640

Référence électronique

Françoise Étienvre, «Entre Mayans y Luzán », Bulletin hispanique [En ligne], 109-2 | 2007, mis en ligne le 01 décembre 2011, consulté le 07 mai 2019. URL : http://journals.openedition.org/

bulletinhispanique/352 ; DOI : 10.4000/bulletinhispanique.352 


\title{
Entre Mayans y Luzán: la necesidad de un Parnaso
}

\author{
FranÇOISE ÉTIENVRE \\ Université Paris III-Sorbonne Nouvelle
}

Une étude comparative des pages et des ouvrages consacrés par Gregorio Mayans et Ignacio de Luzán à la poésie espagnole permet de définir, au delà des différences entre les deux auteurs, une conception du Parnasse régie par des règles précises, propre au Siglo de las Luces.

Un estudio comparativo de las páginas que dedicaron Gregorio Mayans e Ignacio de Luzán a la poesía española permite definir, más allá de las diferencias entre los dos autores, una concepción del Parnaso supeditada a normas concretas, propia del Siglo de las Luces.

A comparative study of the pages and books Gregorio Mayans and Ignacio de Luzán dedicated to Spanish poetry allows one to define, beyond the author's differences, a conception of the Parnassus regulated by precise criteria, specific to the Siglo de las Luces.

Mots-clés : XVIII ${ }^{e}$ siècle - Mayans - Luzán - Rhétorique - Poésie.

$\mathrm{D}$ URANTE mucho tiempo eclipsados por la figura cimera de Feijoo, Gregorio Mayans e Ignacio de Luzán ocupan hoy el puesto que les corresponde al lado del benedictino, y hasta llegan a superarle cuando de temas literarios se trata. Tal vez no está de más recordar que Mayans y Luzán son estrictamente contemporáneos, puesto que el primero nace en 1699 y

$B H i$, Tome 109, nº 2 - décembre 2007 - p. 685 à 708. 
el segundo tres años más tarde. Luego el destino les depara una duración de vida muy desigual, ya que Luzán muere en 1754 y Mayans en 1781, y ese cuarto de siglo de diferencia no deja de tener repercusiones en la producción y en la presencia de ambos hombres en el mundo de las letras dieciochescas. Hoy día se han dedicado al uno y al otro la atención y los estudios que merecen. Sin embargo, pocas veces se les ha reunido para comparar su relación con la poesía y los poetas españoles, una comparación que ha de facilitar, entre otros aspectos, el examen del significado que cobra un - en apariencia - idéntico prurito de constituir y promover un Parnaso español.

\section{MAYANS: LOS PRIMEROS ESCRITOS LITERARIOS ${ }^{1}$}

Gregorio Mayans es un ejemplo relevante, aunque no único en aquel siglo, de un erudito, jurista de formación, capaz de abarcar campos muy diversos y no de manera superficial, sino muy reflexiva: derecho, historiografía, literatura (con el amplio sentido que tenía en aquel entonces la palabra), campo este que más importa en la presente circunstancia. Entre 1725 y 1737 publica una serie de textos relativamente breves, pero de mucha enjundia, sobre la elocuencia (es decir la elocutio, la lengua y el estilo) española.

Cuando se imprime, en 1725, la Oración en alabanza de las eloquentíssimas obras de Don Diego Saavedra Fajardo, Mayans ha ganado dos años antes, en Valencia, la cátedra de Derecho Justiniano y acaba de conseguir un beneficio eclesiástico que le libra de preocupaciones materiales. En el prólogo al lector, declara que concibió primero la Oración como un divertimiento, una manera de ejercitar su pluma "para hacer alarde de algunos españoles dignos de perpetua memoria» ${ }^{2}$, pero que luego pensó "dirigir aquel ensayo a la utilidad pública». Para conseguirlo no se contenta con alabar a Saavedra, el maestro predilecto en cuyos libros pudo observar «la propiedad y grandeza de la lengua castellana», sino que extiende sus observaciones a otros escritores,

1. Dichos escritos han sido estudiados por François Lopez en «Mayans y sus poetas», Actas del Congreso Internacional sobre Gregorio Mayans (Valencia-Oliva, 6 al 8 de mayo de 1999), Ayuntamiento de Oliva, 1999, p. 251-264. Hasta la fecha, el estudio más completo de las obras literarias de Mayans se debe a Jesús Pérez Magallón, En torno a las ideas literarias de Mayans, Instituto de Cultura Juan Gil-Albert, Diputación de Alicante, 1991. Del mismo J. Pérez Magallón se señalará Gregorio Mayans y Siscar. Escritos literarios, Madrid, Clásicos Taurus, 1994 (selección y edición con introducción y notas de varios textos de Mayans, en versión integral o parcial).

2. Obras completas, t. II, Literatura, Oliva, Ayuntamiento, 1984, p. 542. Edición preparada por Antonio Mestre que reproduce la versión de 1739, preferida a las anteriores (1725 y $1735)$ por más perfilada y definitiva. Modernizo la ortografía en las citas. 
reprendiéndoles "con severa, sí, pero justa censura». A continuación justifica con determinación y claridad su método y el fin perseguido: «Ninguna más importante libertad en cosas de letras que la que sin pasión y envidia refiere cómo han escrito los pasados para imitación y enmienda de los presentes y venideros.» El joven Mayans no es tan imprudente como para dar nombres de coetáneos suyos enmendables, pero no queda la menor duda sobre el estilo que quiere censurar, cuando indica que su Oración va dirigida «a los que viven hoy gustosamente enajenados con el embeleso falso de una inútil parlería, hipócritamente suave y armoniosamente lisonjera de tantos y tan incautos oídos» (ed. cit., p. 543). A ese falso brillo opone la "claridad y pureza» que tanto aprecia en Saavedra.

Para el tema que nos ocupa resultan particularmente interesantes las páginas de la Oración en las que evoca Mayans la reacción que suscitaron las quejas de Ambrosio de Morales acerca de la ausencia en su tiempo, exceptuando a Garcilaso de la Vega, de «buenos dechados» que, «leídos y imitados», permitirían una deseable mejora en el uso de la lengua espańola (p. 548). Según Mayans, existe una relación entre estas quejas y la aparición, a fines del siglo XVI y primeros decenios del XVII, de escritores que responden a la exhortación de Morales. Además, considera que la presencia de "un rey amante de la poesía» (se supone que alude a Felipe IV) favoreció la afloración de poetas capaces de «renovar» (no dice superar) la memoria de los mejores poetas de la Antigüedad y, sobre todo, de educar los oídos a percibir y valorar "la suavidad del número» y el artificio de una cláusula «acordemente armoniosa». He aquí la lista de aquellos distinguidos poetas, tal como aparece en la edición de 1739: «don Luis de Góngora y Argote, Lupercio y Bartolomé Leonardo de Argensola, frey Lope Félix de Vega Carpio, don Francisco de Quevedo Villegas, don Juan de Jáuregui, Francisco López de Zárate, el príncipe de Esquilache don Francisco de Borja, don Antonio Hurtado de Mendoza, don Pedro Calderón de la Barca y don Antonio de Solís» (p. 550). A los diez poetas seleccionados en las ediciones anteriores, viene a sumarse, sin justificación, López de Zárate. Tampoco se conoce el motivo de los cambios introducidos en el orden de presentación: Góngora pasa del tercero al primer puesto, Lope de Vega del cuarto al tercero y Quevedo del sexto al cuarto. ¿ Habrá alguna malicia en lo que puede interpretarse como una promoción, sobre todo en el caso de Góngora, objeto de severos ataques, dos años antes, en la Poética de Luzán? Lo cierto es que este primer Parnaso de Mayans incluye tanto a poetas culteranos como anticulteranos, lo que induce a matizar la declarada hostilidad por el barroco que se suele atribuirle. De hecho, se muestra mucho más indulgente con los jefes de fila que con los epígonos sin talento, calificados de «observadores diligentísimos 
de la Aguja de navegar cultos» (p. 560), una sátira de 1631 cuyo blanco queda aún más claro completando el título: "con la receta para hacer soledades en un solo día».

Se muestra Mayans convencido de que una lectura atenta y frecuente de los poetas es imprescindible en la formación de un prosista. Buena prueba de ello es el mismo Saavedra que llegó a la excelencia estilística «no atándose a pueriles reglas en que muchos trabajan vanamente, sino con haber acostumbrado sus oídos a la dulzura de los autores clásicos latinos y buenos poetas castellanos, añadiendo la elección de las palabras y frasis más vivamente expresivas y procurando ajustarlas al primoroso gusto de su delicadísimo oído» (p. 557). Semejante proceso, lento y reflexivo, no tiene nada que ver con la actitud de algunos escritores modernos que a cada paso piden prestado locuciones poéticas con el único fin de «deslumbrar con ellas al necio vulgo» (p. 558), incapaz de conocer el falso brillo.

A pesar de no dar Mayans ningún nombre, se sentirían aludidos varios coetáneos suyos con estas reprensiones, y no serían del todo ajenos a las críticas que suscitó la Oración por haberse atrevido un principiante «a censurar los famosísimos escritos de algunos» ${ }^{3}$. En realidad, los defectos muy puntuales que sin demorarse señala en Cervantes o en Solís, por ejemplo, corresponden a la «severa, sí, pero justa censura» anunciada al principio. De ningún modo redundan en desdoro de los méritos de ambos autores, debidamente alabados además por el supuesto detractor. Esos reproches no impiden que, en la Oración en que se exhorta a seguir la verdadera idea de la eloquencia española (1727), Mayans siga criticando a los que «piensan que hablar perfectamente es usar de ciertos pensamientos que llaman ellos conceptos, debiéndose decir afectados delirios, procurar vestirlos con frasis inventadas, taraceadas éstas de palabras poéticas, extranjeras y nuevamente forjadas, multiplicar palabras magníficas sin elección ni juicio y, en fin, hablar de manera que lo entiendan pocos, y a veces nadie, y ni aun ellos mismos; y por eso lo admiran muchos ignorantes» ${ }^{4}$. Para contrarrestar tan errónea concepción de la «verdadera elocuencia», propone (esta vez, sin el menor reparo) a muchos posibles modelos castellanos, en los que no me detendré por ser todos prosistas.

Es posible que el deseo de contestar a dichas críticas haya contribuido a la orientación sumamente patriótica de la nueva Oración. El fin declarado es animar a los españoles para que saquen su lengua de un lamentable estado de

3. Son palabras del mismo Mayans, sacadas de su Maiansii vita y reproducidas por A. Mestre en su edición de las Obras completas, op. cit., p. 7.

4. Ed. cit., p. 569. También en este caso, reproduce A. Mestre la última versión de la Oración (1739). 
degeneración, tanto más cuanto que, en el mismo tiempo, han progresado notablemente las demás lenguas europeas. Creo que es único, bajo la pluma de Mayans, el llamamiento que remata la Oración: «Está España infamada de poco elocuente. Vindicad su honra, españoles. Generosísimos espíritus, vindicad la vuestra» (p. 582).

Unos años más tarde, cuando redacta El orador christiano, ideado en tres diálogos (1733), vuelve Mayans sobre lo difícil, y hasta peligroso, que resulta en España criticar, incluso de manera objetiva, lo que tradicionalmente se considera como bueno: «La censura particular no se sufre, aunque sea de los muertos, por ser contraria a la opinión de los vivos.» ${ }^{5}$ Con todo, no desiste de seguir publicando sus opiniones sobre la reforma de la elocuencia española y, más concretamente esta vez, de la oratoria sagrada. Si tal es el tema principal de los diálogos entre Fabio y Lucrecio, muchas páginas tratan sin embargo de aspectos relacionados con la poesía.

Una vez más insiste Mayans en la necesidad de no mezclar los diferentes estilos, puesto que «La elocución o es filosófica, u oratoria, o poética» ( $\$ 127$, p. 88). Sin embargo, aunque «la poética se aparta mucho del común modo de hablar» (ibid.), puede inspirar a los prosistas y oradores, ennobleciendo además su estilo, con tal de que sea natural la expresión. Para demostrarlo, aduce varios ejemplos entre los cuales sorprende una detenida referencia a Góngora y más aún, como bien lo advirtió François Lopez, su enlace con Manrique para ilustrar el estilo poético natural:

Ningún poeta ha tenido Espańa tan apartado del común modo de hablar como don Luis de Góngora; sin embargo, vea Vm. qué locuciones estas tan propias del lenguaje de todos, aunque con una alteza de pensar propia suya. [Cita el soneto «A una rosa»] ¡Valiente pensar! Con semejante estilo, y aun mucho más natural, compuso don Luis sus romances y también sus letrillas, y se explicó de manera que, cuando quiso hablar sin afectación, se hizo inimitable. Vea Vm. qué expresiones estas tan naturales y gallardas [cita la letrilla «Dineros con calidad»]. En este mismo estilo están compuestas aquellas juiciosísimas y nunca bastantemente alabadas coplas de Jorge Manrique, blasón perpetuo de la nobleza española [cita los doce primeros versos de las coplas "por la muerte de su padre»].

$(\$ 127$, p. 89-90)

Revelan claramente estas líneas que dista mucho Mayans de rechazar globalmente la poesía gongorina: su reserva frente a los poemas escritos con «afectación» está mencionada, pero de paso, y queda ampliamente superada por la sincera admiración que le inspira sobre todo el poeta de los romances y las letrillas.

5. Idem, p. 23. 
Aunque pueda extrañar en un hombre que combate como «defecto general de la nación, el hablar demasiadamente metafórico, sin propiedad ni pureza» ( $\$ 139$, p. 93$)$, manifiesta Mayans un auténtico gusto por la poesía que considera como un mundo aparte, con sus normas propias, un mundo excepcional por el cual siente el mayor respeto. El alto concepto que tiene de la poesía se percibe de manera nítida a la hora de señalar modelos para la formación del orador a quien aconseja «leer algunos poetas, los mejores, no tanto por el gusto de que se privaría como porque su lección fomenta mucho la elocuencia» ( $\$ 154$, p. 96). Lo que espera de una obra poética explica que sean pocos los elegidos:

No podemos negar que en las obras de los poetas se halla un
dmirable espíritu; en sus afectos, movimientos grandes; en las
personas que introducen, el decoro o decencia correspondientes a
ada una de ellas; en las palabras, nobleza; y en su estilo, magnificencia
sublimidad. Verdad es que los poetas que nosotros tenemos en
quien estas partes se hallen son poquísimos. Bastará leer a Garcilaso
de la Vega, a Cristóbal Virués en su Montserrate, al padre maestro
ray Luis de León, a los hermanos Leonardos, y a tal cual otro cuyas
lumas no se hayan manchado en suciedades; y alabaría yo mucho
l que entresacase las mejores poesías de los más aventajados poetas
spañoles y nos diese una media docena de libros en que no hubiese
osa que desechar. ( $\$ 154$, p. 96$)$

No habría que sacar conclusiones precipitadas sobre la evolución del gusto de Mayans a partir de esta nueva lista, mucho más restringida que la anterior, puesto que está constituida para el orador cristiano, lo que supone que queden descartadas las poesías livianas y chocarreras. Sin embargo, han de destacarse los nombres de Garcilaso, fray Luis y los Argensolas por aparecer ya citados como modelos en los precedentes discursos. Así van cobrando poco a poco un valor de total ejemplaridad, por lo menos en la mente de Mayans. Más notables aún son las frases en que está formulado el deseo (en el siglo XVIII, Mayans es uno de los primeros, sino el primero, en hacerlo) de que se componga un Parnaso español, fundado en una rigurosa selección. Parnaso español, es precisamente el título escogido para la Colección de poesías escogidas de los más célebres poetas castellanos, elaborada mucho más tarde por López de Sedano y uno de los discípulos predilectos de Mayans, Cerdá y Rico, colección que consta de nueve volúmenes y que se publica entre 1768 y 1778.

Prosiguiendo su reflexión sobre la lengua y las letras españolas, en 1737 publica Mayans los Orígenes de la lengua española y la Vida de Miguel de Cervantes. Se recordará que el mismo año también sale a luz la Poética de 
Luzán. El primer texto prolonga la Oración en que se exhorta a seguir la verdadera idea de la eloquencia española puesto que, fiel a las doctrinas de la Antigüedad, establece Mayans una conexión entre gramática y retórica, entre la historia de una lengua y la ideal estructura sintagmática del discurso. La poesía no aparece en este discurso, sino de manera anecdótica: al tratar de las lenguas de Espańa y, entre ellas, de la lemosina, evoca el valenciano a los poetas que, de Arnaldo Daniel a Ausias March, la ilustraron en la Edad Media. Se da así un gusto personal manifestando que una lengua, que muy a pesar suyo está cayendo en desuso, tiene sin embargo sus cartas de nobleza. Más conocida es la Vida de Cervantes, extenso prólogo destinado a servir de introducción a la magnífica edición inglesa del Quijote, costeada por lord Carteret. Son páginas fundamentales cuando quiere estudiarse la lectura de la obra cervantina a lo largo de los siglos; en cambio, lo son mucho menos desde nuestra perspectiva, dado que la poesía solo está presente a través de abundantes noticias sobre todos los poetas mencionados en la novela.

\section{LA RHETÓRICA}

Publicados en 1757, los dos gruesos tomos de la Rhetórica vienen a rematar la reflexión sobre la elocuencia española emprendida por Mayans más de treinta años antes. Ya en El Orador christiano había manifestado su deseo de componer una oratoria de concepción nueva que tenía bien ideada, pero que no tuvo tiempo ni paciencia de llevar a cabo:

Dar a los preceptos nuevo método no sería difícil, pero ilustrarlos con ejemplos escogidos, quiero decir, no copiados de las demás retóricas, sino observados en las Divinas Escrituras y en las obras de los Santos Padres y de algunos pocos modernos, sabios y elocuentes, pedía dos o tres años de anticipada lección y observación muy sagaz, porque si uno intentase valerse únicamente de aquellos ejemplos que la memoria le ofreciese, tengo por cierto que en gran parte no serían tan buenos como debieran ser; y si quisiese valerse de otros mejores, estos no tanto se hallan, cuando de propósito se buscan, como impensadamente, leyendo y observando para diferentes fines lo mejor que se lee. Y así confieso que me faltó la paciencia para tan larga empresa. (\$10, p. 21)

Esta paciencia la tuvo para componer la Rhetórica, entre cuyas novedades destaca la abundancia de ejemplos, todos en castellano, con excepción de unos pocos versos de Camóes citados en portugués. El mismo Mayans destaca este aspecto como original, cuando presenta al P. Andrés Marcos Burriel la obra que está limando: «la erudición es griega y latina en los 
preceptos, española en los ejemplos [... ${ }^{6}{ }^{6}$. Dichos ejemplos, además, no son inventados ni copiados de otras retóricas, sino fruto de lecturas personales y de un meditado trabajo de selección : «De la letura me he aprovechado para valerme de ejemplos de escritores españoles, los más escogidos, que se han ofrecido a mi memoria; porque el que no tiene buen dechado, no puede ser buen remedador.» ${ }^{7}$ Muy tradicional es la función atribuida en estas líneas a los textos elegidos, pero Mayans nunca puso en duda el beneficio que uno podía sacar de la imitación de buenos modelos. Ni siquiera le hizo cambiar de parecer la opinión contraria de Feijoo que, en las Cartas eruditas, se había mofado de Mayans de manera ofensiva, atribuyéndole la pretensión (que nunca tuvo) de querer igualar a su maestro Saavedra ${ }^{8}$. Pero bien se sabe que la enemistad explica en gran parte esa aparente división de opiniones.

Además de favorecer la imitación, los ejemplos le permiten al autor de la Rhetórica «ostentar las riquezas de la lengua castellana, desenterrando al mismo tiempo la memoria de muchos escritores puesta ya en olvido, siendo así que son los maestros de la pureza de la lengua» ( $\$ 60$, ed. cit. p. 71). La búsqueda y la selección de los textos corresponden, por lo tanto, a una voluntad de rescatar y de reivindicar un patrimonio literario valioso $y$, sin embargo, ignorado de muchos. Es comparable tal voluntad a la de un Sarmiento que, también por aquellos años, se entrega a una labor de arqueología literaria para proporcionar datos nuevos sobre los orígenes de la poesía española cuya historia, insiste en ello, está por escribir. Repetidas veces expresa en sus Memorias ${ }^{9}$ el deseo que, tras la debida revisión de los manuscritos, se impriman las obras completas de poetas anteriores al siglo XVI. Consciente de que interesaría sobre todo «a los que se divierten con

6. Carta del 16 de noviembre de 1754, Epistolario II. Mayans y Burriel, editado y anotado por A. Mestre, Valencia, Publicaciones del Ayuntamiento de Oliva, 1972, p. 583.

7. Gregorio Mayans y Siscar, Obras Completas, III, Retórica, ed. preparada por A. Mestre, Valencia, Publicaciones del Ayuntamiento de Oliva, «A los letores», $\$ 58$, p. 69. A. Mestre reproduce el texto de la segunda edición (1786-1787), señalando en las notas las variantes de la primera edición.

8. «Un ejemplar que muestra cuán expuestos están los hombres a errar en el concepto de que imitan tal o tal estilo, me presenta cierto escritor moderno, por otra parte muy capaz, que está persuadido a que su pluma es fiel copista de D. Diego Saavedra, cuando los demás hallan de uno a otro estilo la diferencia que hay del noble al humilde, del enérgico al flojo y del vivo al muerto.» (Feijoo, Cartas eruditas, t. II [1745], carta 6, «La elocuencia es naturaleza y no arte», p. 40-41 en la ed. de Agustín Millares Carlo, Madrid, Espasa-Calpe, Clásicos Castellanos, 1969).

9. Fr. Martín Sarmiento, Memorias para la historia de la poesía, y poetas españoles, Madrid, J. Ibarra, 1775, t. I de las Obras pósthumas. 
esas antigüedades» (\$ 727), al mismo tiempo está convencido de que la publicación de aquellas poesías contribuiría a una revalorización de las letras españolas.

Comentando con Burriel la necesidad de renovar la retórica española al uso, observa Mayans: «Y si bien reparamos, es grande mengua de los ingenios que nada haya añadido a la retórica después de Aristóteles, su primer perficionador; y este filósofo, aunque tan agudo, más tiró a reducir a arte los ejemplos que a manifestar las causas de la perfección de los ejemplos.» ${ }^{10}$ Largos años de reflexión le han convencido de que el esfuerzo de renovación no ha de recaer tanto en la doctrina como en los ejemplos aducidos y en el uso que de ellos se hace. Aboga por una retórica que, en vez de limitarse a acumular preceptos, también presente un análisis de las razones que llevan a considerar un texto como modélico, a entender por qué se admira o se aprueba a un escritor. No se equivocaba en la vía que había decidido escoger y que pocos habían explorado en España.

Por fin indica Mayans que, al seleccionar textos para la Rhetórica, tuvo en cuenta un criterio más: eligió «ejemplos tales [...] que al mismo tiempo que ilustren los preceptos retóricos, instruyan a los estudiosos, o en la filosofía moral, o en la política, o en las obligaciones cristianas, de suerte que esta obra no solamente sea una retórica entera y cabal, sino también un manual de filosofía y política cristiana.» (\$ 58, p. 70) Es una declaración, o aclaración, que expresa una concepción global del ser humano, en la cual van estrechamente unidos lo intelectual y lo espiritual. Muchas son, pues, las funciones atribuidas a los ejemplos en la Rhetórica: imprescindibles para la imitación, también han de servir para ilustrar preceptos, practicar el análisis de los textos, conocer mejor la literatura española y participar a la formación moral del lector, lo que explica la importancia que les otorga Mayans.

Se caracterizan los ejemplos citados por su abundancia y, muy a menudo, por su extensión: trátese de prosa o de verso, el texto reproducido puede ocupar dos páginas o más, y así se justifica que se haya considerado la Rhetórica también como una antología. Que esté bien representada la poesía no ha de extrañar si se recuerda el papel que, siguiendo a Quintiliano, le atribuye Mayans en la formación de un hombre de letras y que reafirma en su nueva obra ${ }^{11}$. Vuelve a evocar las características de la escritura poética, sus privilegios y sus dificultades, con términos muy parecidos (a veces idénticos) a los que había usado en escritos anteriores, y con la claridad que impone un propósito didáctico :

10. Carta del 9 de enero de 1745, op. cit., p. 59.

11. Ver, en particular, Libro III, cap. I, $\$ 63$, éd. cit., p. 318. 
La elocución o es prosaica o poética. Esta última se aparta mucho del modo común de hablar en la invención de las cosas, en su disposición, en las palabras, en su colocación, composición y adorno. En la invención de las cosas, porque puede decir las que pudieron y debieron suceder. En su disposición, porque no se ata al orden natural, y por eso puede empezar la narración por el medio, o cerca dél, para hacerla más agradable. En las palabras, porque tiene muchas que son propias de la poesía y no de la prosa, y es más abundante de epítetos. En la colocación de las palabras, porque tiene mayor licencia en la trasposición de ellas. En la composición de las palabras, porque la poesía es más harmoniosa, por estar atada a cierto número de pies de ciertas medidas, y tal vez a la rima. En el adorno, porque la elocución poética admite mayor ilustración en las descripciones, mayor licencia en los episodios y en las figuras, así de sentencias como de palabras. (Lib. III, cap. I, $\$ 1$ p. 307)

Sigue concibiendo la poesía como un mundo regido por normas propias, que goza de una libertad impensable en la prosa. Tampoco ha cambiado de parecer sobre el beneficio que puede sacar un prosista de la lectura de poetas, con tal de que no olvide que cada escritura tiene sus pautas. A los que criticarían la presencia, en una retórica, de consideraciones que suelen leerse en poéticas, responde Mayans que «la poética es parte de la retórica», asentando su afirmación en la autoridad de Aristóteles que «trató de ella [la poética] y de los poetas en sus libros retóricos, y se valió de sus ejemplos [...]» (Lib. II, cap. XII, \$32, p. 278).

Queda por examinar lo que más importa para nuestro tema, a saber quiénes son los poetas escogidos en la Rhetórica, cuál es su papel y hasta qué punto constituyen un Parnaso español. La gran mayoría de los poetas seleccionados (una tres cuarta parte) pertenece al siglo XVI, y los demás a los siglos XIV, XV y XVII. Lo mismo que en los escritos anteriores, no menciona Mayans a ningún coetáneo, probablemente porque al indicar preferencias, hubiera suscitado reproches y disputas que prefería evitar. $Y$ es de notar que su prudencia fue imitada por casi todos los que compusieron antologías en la segunda mitad del siglo XVIII.

La fama de los autores citados no es el único criterio de selección, puesto que al lado de nombres tan conocidos como los de Juan Manuel, Jorge Manrique, Garcilaso, Góngora o Lope de Vega (la lista no es exhaustiva), aparecen otros menos prestigiosos (fray Ińigo de Mendoza, Pedro de Cartagena, Francisco de la Torre, por ejemplo), y también algunos injustamente olvidados según Mayans. Entre ellos figura Francisco de Aldana, del cual da frecuentes y largos extractos "por ser sus obras raras y poco leídas" (Lib. I, cap. XXI, 
$\$ 15$, p. 138 ${ }^{12}$. Como en otras muchas ocasiones, no se olvida Mayans de la patria chica con la mención de "un ingenioso poeta valenciano», Francisco de Castellví, y de Jerónimo de Artés.

Como en cualquier otra retórica, los ejemplos, que también pueden ser contraejemplos, aparecen estrechamente relacionados con el punto tratado. Sin embargo, la extensión de muchas citas revela que la función de los textos reproducidos no se limita a la ilustración de un precepto. Antes que todo están destinados, como ya se ha dicho, a despertar el interés por un autor o una obra poco conocida u olvidada y, en todo caso, a favorecer un conocimiento más concreto y reflexivo de los méritos de un escritor más o menos famoso. Sin embargo, no le presta Mayans mucha ayuda al lector para la comprensión de los mecanismos literarios. La presentación del extracto casi siempre se limita a unos calificativos elogiosos, que no son de mero cumplido. En muy contadas ocasiones ańade Mayans unas explicaciones sobre las razones de su elección, como en esta introducción a una égloga de Garcilaso:

[...] vemos que Garci-Lasso de la Vega, hombre de grande ingenio y de mayor dulzura en el decir, y príncipe en este género de composición, sin faltar al decoro debido a las personas, a lo que conviene a la materia y al arte de tratar de ella, cantó en su Égloga segunda con incomparable elegancia y dulzura las alabanzas de la vida pastoril deste modo: [cita de la égloga] (Lib. III, cap. XXII, $\$ 3$, p. 535).

Además de las dotes peculiares de Garcilaso, la perfecta adecuación (afirmada, y no demostrada) de su égloga a las normas que rigen esta forma poética justifica, por lo tanto, su estatuto de modelo. Nunca va más lejos Mayans en la demostración. En realidad, su meta principal es brindar textos que formen el gusto y aumenten las ganas de leer.

Se habrá comprobado que, desde el principio, Garcilaso ocupa en el Parnaso de Mayans un puesto destacado, confirmado en la Rhetórica, donde se alaban con frecuencia la elegancia, la dulzura, la musicalidad ${ }^{13}$ de sus versos. A su lado aparecen unos cuantos más poetas, cuya lista establece Mayans después de advertir que son pocos los que merecen la apelación de «buenos escritores», y que "por eso es menester gran juicio para distinguir y elegir los mejores, entre los cuales ciertamente podemos contar, [...] de los poetas: a Garcilaso de la Vega, a Juan Boscán, a don Diego Hurtado

12. En el prólogo a la edición citada de la Rhetórica (p. XXII), Jesús Gutiérrez recapitula los textos de Aldana seleccionados por Mayans.

13. Véase al respecto un intento de demostración concreta de dicha musicalidad a partir de la sonoridad de las palabras y de las letras en el lib. III, cap. XVII, p. 485 y sigs. 
de Mendoza, a Francisco de la Torre, al maestro fray Luis de León, a los hermanos Argensola, y a otros pocos» (Lib. III, cap. I, $\$ 67$, p. 319, n. 59). En la segunda edición, publicada treinta años después, unos pocos están añadidos, y la nueva lista cuenta entonces «a D. Jorge Manrique, a Garcilaso de la Vega, a Juan Boscán, a Cristóbal de Castillejo, a D. Diego Hurtado de Mendoza, a fray Luis de León, a Gregorio Hernández de Velasco, a Cristóbal de Virués, a Francisco de la Torre, a D. Esteban Manuel de Villegas, a los hermanos Argensolas, y a otros pocos» (ibid.). Importa señalar que, a continuación, aclara Mayans el interés que representa semejante esfuerzo de selección: "Para formar el estilo deben leerse con gran frecuencia muy pocos y los mejores; pero una vez formado, conviene estender la leyenda a otros muchos, para adquirir una gran abundancia de palabras y de cosas [...]». Los escritores que figuran en la lista, considerados como «los mejores», corresponden por consiguiente a una primera etapa, la de la formación del estilo a través de la observación e imitación. Al proponer muchos más textos de otros autores, la Rhetórica cumple también con el segundo propósito expresado, el de ampliar los conocimientos del lector.

Que haya variaciones de una edición a otra no extraña, ya que se había constatado un fenómeno parecido en escritos anteriores. Sin embargo, la composición de ambas listas requiere algunos comentarios. La mayoría de los poetas que figuran en la primera representan para Mayans valores seguros, puesto que ya los había alabado o seleccionado. Francisco de la Torre es el único, si no me equivoco, en aparecer por primera vez entre los mejores. Algunos nombres añadidos en la segunda edición corresponden a la corrección de un olvido: es el caso de Manrique, de Virués, ya señalado como modelo por su Monserrate en el Orador christiano, o de Villegas, cuyas Eróticas están citadas muy a menudo y con elogio en la Rhetórica. En cambio, sorprende la presencia de Gregorio Hernández de Velasco, traductor de Virgilio, o la de Cristóbal de Castillejo mencionado, tan solo en la segunda edición, como glosador de Manrique, y de los cuales están reproducidos muy pocos versos. En su lugar se esperaría a Torres Naharro, presentado como "el poeta satírico más aventajado hasta hoy» ${ }^{14}$, a Ercilla, «segundo Lucano español», de cuya Auracana se leen muchísimos extractos en la Rhetórica, a Aldana o a Arias Montano, ambos muy apreciados por Mayans que, tal vez, no se atrevería a presentar como indiscutible un gusto personal. Incitan a pensarlo unas frases suyas de una carta a Burriel en la que equipara a Arias Montano con Horacio, revelando su confianza en la capacidad de los poetas modernos, cuando saben valerse de los antiguos:

14. Lib. II, cap. XII, \$15, p. 262. 
De sus Odas [las de Horacio] no hablemos porque son incomparables, como no se cotejen con las de Arias Montano. Y esto lo digo sin que nadie nos oiga para que no haya quien se escandalice de mí. [...] ¿Hay por ventura cosa buena en los antiguos poetas griegos y latinos que Montano no haya imitado? ¿o es verdad que sus poesías incluyen toda la Historia Sagrada? ¿No es cierto que el estilo es purísimo? ¿ ¿No es evidente que el juicio es admirable? ¿¿No se siente en el corazón que Dios le inflama? ${ }^{15}$

Imitación perfecta de los modelos de la Antigüedad, ciencia religiosa y elevación espiritual, pureza del estilo: según los criterios de Mayans, podía entrar Montano en el Parnaso español, y el sitio que le reserva en la Rhetórica es una manera de encaminarle hacia aquella cumbre.

Otra sorpresa que reserva tan selectiva lista es la exclusión de los más famosos poetas distinguidos en la Oración en alabanza de [...]Saavedra Fajardo, Góngora, Lope de Vega, Quevedo, muy presentes los dos primeros en la Rhetórica, pero a la vez «alabados» o «reprehendidos», según la terminología de Mayans. Tanto Lope como Góngora son alabados por sus dotes naturales, su ingenio, su gracia y habilidad. No cabe duda de que el autor de la Rhetórica los considera como poetas que dominan perfectamente su arte, y por eso los cita a menudo cuando quiere mostrar la aplicación lograda de un precepto. Casi todos los ejemplos de Lope proceden de las Rimas. En cuanto a Góngora, predominan los romances y las letrillas, y menudean los versos que ilustran su excepcional habilidad técnica, o su capacidad a manejar el estilo festivo y jocoso ${ }^{16}$; pero también está presente la poesía lírica, como en el soneto a la rosa que le gusta particularmente a Mayans, puesto que ya lo había citado en El Orador christiano. El erudito y serio valenciano no se muestra reacio a las gracias y a los donaires en la poesía, considerándolos como propios del descanso, pero recuerda que deben usarse con discernimiento ${ }^{17}$.

El ingenio natural de aquellos poetas puede llevarles a excesos «reprehensibles», señalados lo mismo que los aciertos en la Rhetórica. Así se hallan reunidos Quevedo y Góngora en una clara crítica de lo que Mayans llama el «estilo ridículo», degeneración de lo agraciado:

15. Carta del 28 de mayo de 1746, Epistolario, ed. cit., p. 265.

16. Véanse, por ejemplo, lib. V, cap. IX, $\$ 12$, p. 636, unos versos en que Góngora reduce a consonancia rímica una fábula de Isopo. Se dan unas muestras, entre otras muchas, de procedimientos del estilo festivo o jocoso lib. III, cap. XIV, $\$ 73,76$, p. 452, 454, $\$ 83$, p. 456 , y cap. XV, $\$ 20$, p. 472.

17. Mayans dedica un largo párrafo a lo que distingue la gracia de la chanza, con el modo de usarlas (lib. V, cap. IV, \$21, p. 599). 
Don Francisco de Quevedo Villegas se dedicó mucho al estilo ridículo; y no pocas veces le afectó don Luis de Góngora anteponiendo el aplauso popular al de los eruditos juiciosos. Quizá conocía su poca erudición original y el gusto estragado de la mayor parte de los contemporáneos, faltos de las letras de humanidad, y tenía por máxima escribir a contentamiento de sus letores lo que dice en unas letrillas hechas al desengaño, después de haber hablado con seriedad:

\author{
¿Pero quién me mete \\ En cosas de seso, \\ $\mathrm{Y}$ en hablar de veras \\ En aquestos tiempos? \\ Porque el que más trata \\ De burlas y juegos, \\ Ese es quien se viste \\ Más a lo moderno ${ }^{18}$.
}

Por otra parte estima Mayans que también se excedieron en la elaboración de muchas metáforas que él juzga «lejanas», es decir demasiado alejadas de la realidad. Entre los ejemplos aducidos, se lee un verso de Góngora, sacado del Polifemo: «Era un monte de miembros eminente», presentado como un caso de «abusión» o "catacresis». Carece dicho verso de "semejanza», fundamento de la metáfora para Mayans, que explicita de este modo su rechazo: «Porque es cierto que Polifemo, por alto que fuese, no podía tener proporción en la altura con un monte eminente» (Lib. III, cap. V, $\$ 26$, p. 338). Su imaginación no estaba dispuesta a dar el salto ecuestre (hablando en términos lorquianos) que supone la creación y la comprensión de una metáfora. Con todo, es de notar que este es el único verso del Polifemo criticado en la Rhetórica que, además, no menciona las Soledades. Solo en una brevísima frase, que pudiera pasar desapercibida, está evocada «la oscuridad", defecto tantas veces achacado a Góngora por aquel entonces ${ }^{19}$. Aún más censurable le parece a Mayans que, en sus juegos metáforicos, se inspiren los poetas en «cosas puercas» o sagradas, y en ambos casos Góngora está entre los «reprehendidos» ${ }^{20}$. Peor todavía «es abusar de las traslaciones

18. Lib. III, cap. XXIII, $₫ 13$, p. 544 . Repite Mayans la misma crítica lib. V, cap. IV, $\$ 20$, p. 599.

19. «Hase de quitar la oscuridad, por la cual han sido reprehendidos muchos escritores, como fray Hortensio Felis Paravicino en la prosa, y don Luis de Góngora en el verso» (lib. V, cap. IX, $\$ 39$, p. 643).

20. Ejemplos de inspiración en "cosas puercas» : «Cuando ha de echarme la musa / Alguna ayuda de Apolo, / Desatácase el ingenio / Y algunos papeles borro» (lib. III, cap. V, $\mathbb{\$} 33$, p. 339). Ejemplo en contra de lo sagrado : «[...] cuando Góngora, escribiendo en un soneto 
impíamente; de las cuales será mejor no alegar ejemplos, aunque abunda de ellos don Francisco de Quevedo Villegas en sus obras burlescas» ( $\$ 38$, p. 340). La falta de decoro (formal o moral) y la impiedad no tenían cabida en una concepción de la literatura que incluía en sus fines la educación moral y cristiana del lector.

De esos reproches se libran Garcilaso, Manrique y, más aún, fray Luis de León, el poeta predilecto de Mayans que ve en él la «grandeza de decir adornada de la harmonía métrica» (lib. I, cap. XXIV, \$ 87, p. 175). Los breves comentarios que acompañan los numerosísimos extractos de fray Luis revelan a un Mayans particularmente sensible a la belleza de los poemas que celebran a Dios, a un estilo que él llama «la divina manera de cantar». Una profunda fe católica no es ajena a tan pronunciada admiración que lo lleva luego a redactar una Vida del maestro Fr. Luis de León. Esta Vida forma parte de los preliminares a las Obras de fray Luis, publicadas en Valencia, en 1761, por iniciativa de Mayans que encomendó el trabajo editorial a un discípulo suyo, Vicente Blasco. Esas páginas le permiten expresar detenidamente los motivos de su predilección por unos poemas que «son los que más ennoblecen la lengua espańola; porque si ser poeta consiste en una especie de ficción en que perfectamente se imita la naturaleza y las propiedades y circunstancias de las personas y de las cosas, el maestro León manifestó tener un ingenio sutilísimo para la invención, y una destreza tan feliz para expresar noblemente lo inventado que no solo supo declarar noblemente sus propios pensamientos, sino también trasladar los ajenos de una lengua en otra, que es mucho más difícil» (Vida, $\$$ 58 ${ }^{21}$. Para Mayans, si tanto destaca la poesía de Fr. Luis es porque sigue perfectamente el canon clásico, al mismo tiempo que revela ingenio, dominio del arte, nobleza del pensamiento y de la forma, tanto en la poesía de creación como en la traducción de los Salmos. También es significativo que, en dicha Vida, viene asociado al elogio de Fr. Luis el de Arias Montano que, declara Mayans, «entre los poetas cristianos latinos ha sido, a mi jucio, el más sublime en los pensamientos y más diestro en la manera de expresarlos con propiedad y elegancia» (Vida, $\$ 22$ ).

Fr. Luis es sin duda alguna el príncipe del Parnaso español de Mayans, por motivos objetivos y personales. Los poetas que están a su lado en la reducida lista propuesta en la Rhetórica tampoco le han sido impuestos a Mayans por la fama; los ha elegido porque corresponden a unos criterios claramente enunciados al principio de su libro y, por consiguiente, los puede

las novedades de la corte y queriendo decir que se frecuentaba muy poco la casa de las comedias, lo expresó así : Dada la extrema unción a la comedia» (\$37, p. 340).

21. P. 336 en la edición de J. Pérez Magallón ya citada (nota 1). 
proponer sin temor como modelos, a la vez artísticos y morales. Por el mismo motivo puede explicarse que quedan excluidos algunos tan célebres como los elegidos, e incluso más. También influirían en la decisión de descartar a poetas que hoy llamamos barrocos, las repetidas censuras que sufrían en tiempos de Mayans, aunque este se muestra muy moderado en sus críticas, que recaen en puntos concretos y no en la totalidad de una obra. Además, al lado del restringido Parnaso oficial, se autoriza Mayans a constituir con los mismos criterios otro más personal, destinado a despertar la curiosidad del lector y, por consiguiente, mejorar su conocimiento de la poesía española.

\section{LA POÉTICA DE LUZÁN (I737)}

No cabe la menor duda de que Mayans conocía la obra de Luzán, pero nunca la menciona en la Rhetórica publicada, sin embargo, veinte años después. Tan sorprendente silencio no ha de interpretarse como una señal de reprobación, sino más bien como la manifestación de un deseo de ignorar a quien se había relacionado con el grupo de los que el valenciano consideraba como sus enemigos en la Corte, capitaneados por Montiano. Ocioso sería demorarse en rencores e inquinas que no vienen al caso; más importa examinar la doctrina poética de Luzán y su concepción del Parnaso español para comparararlas con las de Mayans.

Sabido es que Luzán, por motivos familiares, se educó en Italia y que pronto mostró gran interés por la poesía. Por los ańos en que Mayans daba a luz sus primeros escritos literarios, Luzán acudía en Palermo, y luego en Nápoles, a las juntas de unas academias literarias, lo que le llevó a redactar unos discursos de teoría poética. Cuando vuelve a España, en 1733, tiene grabados en la mente los reproches que se hacen en Italia, y también en Francia, a la poesía española (comedia incluida), culterana y conceptista. Publica en 1737 una Poética que tenía bastante adelantada al salir de Nápoles, anticipándose, probablemente sin saberlo, al proyecto de la Real Academia Española que juzgaba la elaboración de una Poética tan necesaria como la de una buena gramática: «Fenecido el Diccionario [...] se trabajará en una Gramática y una Poética españolas, e Historia de la lengua, por la falta que hacen en Espańa. Y en cuanto a la Retórica, podrá excusarse de trabajar de nuevo, porque hay bastante escrito» ${ }^{22}$. Luego demostró Mayans que también en la retórica podían introducirse innovaciones y mejoras.

22. Estatutos de la Academia (cap. quinto, estatuto primero), firmados en 1715. Están reproducidos al principio del Diccionario de Autoridades, p. XXIX. 
En el Proemio que encabeza la Poética, Luzán expresa con toda claridad los motivos que le llevaron a imprimir su voluminoso tratado y el fin que persigue. Antes que todo quiere luchar contra «la corrupción de la poesía del siglo pasado, particularmente en lo que toca al teatro" ${ }^{23}$. Está convencido de que tal corrupción en gran parte procede del poco interés manifestado por los espańoles (a diferencia de los italianos y los franceses) por la doctrina poética. Menciona los escritos de unos preceptistas del siglo anterior, Cascales y González de Salas, pero les reprocha cierto apocamiento a la hora de imponer sus puntos de vista, sin duda por no atreverse a ir en contra del gusto del público. Puesto que no bastaron sus esfuerzos para acabar con lo que él considera como extravagancias de la poesía española, se propone ofrecer a sus compatriotas "un entero, cabal y perfecto tratado de poética». Tiene conciencia de que pocos considerarán necesario su tratado y que, además, puede suscitar reacciones de hostilidad. No basta eso para detenerlo. La fuerza de su convicción procede de la autoridad que, a sus ojos, dan a los preceptos que expone en su libro dos mil años de existencia. Recuerda que aquellos preceptos se comentaron y discutieron en todas las naciones civilizadas para facilitar su aplicación universal. Afirma que las normas heredadas de la Antigüedad siempre pueden profundizarse y adaptarse al espíritu de una época, como lo demuestra la reflexión teórica de calidad llevada a cabo, en este principio del siglo XVIII, por un Muratori, verdadera Biblia para Luzán, o un Crousaz ${ }^{24}$. La atención prestada a esta clase de tratados explica que naciones como Italia y Francia, en particular, ya pueden "caminar, sin tropiezo ni extravío, la vuelta del Parnaso» (p. 124). Espera, por lo tanto que su libro permitirá que «el público, a la luz de evidentes razones, reconozca finalmente el error y deslumbramiento de muchos, que más ha de un siglo hasta ahora, han admirado como poesía divina la que en la censura de los entendidos y desapasionados está muy lejos de serlo» (p. 128). Lo que pretende Luzán es nada menos que una total revisión de los valores establecidos en materia literaria, y revela su meta con una seguridad, por no decir un sentimiento de superioridad, fundada en una ciencia adquirida, seguridad que también manifiesta Mayans.

Aclarada la posición inicial de Luzán, queda por examinar su visión de la poesía española, si existe para él un Parnaso nacional y, en este caso, cuáles son los requisitos para ser digno de integrarlo. Dado que, hoy día, la palabra

23. p. 125 en la edición de La Poética de Russell P. Sebold, Barcelona, Ed. Labor, 1977.

24. Hace referencia Luzán al tratado de Muratori, Della perfetta poesia italiana (1706) y al Traité du Beau de Crousaz (1715). 
Parnaso suele remitir tan solo a los poetas, no incluiré en este examen a los autores de comedias, aunque sean el objeto del libro III y de unas cuantas páginas más en la Poética.

Del «perfecto poeta», tenía Luzán una concepción que no podía desaprobar Mayans:

No digo que, para formar un perfecto poeta, no sea absolutamente necesario el ingenio y natural talento; pero digo con Horacio que eso solo no basta sin el arte y estudio y que el compuesto tan feliz, como raro, de arte e ingenio, de estudio y de naturaleza, es el que solo puede hacer un poeta digno de tal nombre y del aplauso común. (p. 125)

Y se declara luego convencido de que, por desestimar esta doctrina, varios poetas del siglo anterior no consiguieron alcanzar las cumbres a las cuales les destinaba su natural talento. A principios de dicha centuria fue cuando, según él, empezaron a degenerar la elocuencia y la poesía española:

[...] se perdió casi del todo la memoria de aquellos insignes poetas anteriores, que pudieran haber servido de norma y dechado a los modernos. Y estos, con el vano, inútil aparato de agudezas y conceptos afectados, de metáforas extravagantes, de expresiones hinchadas y de términos cultos y nuevos, embelesaron al vulgo; y, aplaudidos de la ignorancia común, se usurparon la gloria debida a los buenos poetas. (p. 126)

Así define el estilo que quiere combatir, y lo hace con términos que vuelven a aparecer a lo largo del siglo bajo la pluma de muchos literatos.

Al esbozar una historia de la poesía espańola, da Luzán unas cuantas indicaciones sobre los que considera como «insignes poetas», dignos de convertirse en «dechados». Menciona con elogios al marqués de Santillana, a Boscán, a Diego Hurtado de Mendoza, a Gutierre [sic] de Cetina y, sobre todo, a Garcilaso «que se remontó más que todos y mereció ser llamado el príncipe de la lírica española» (p. 135). Va hasta declarar que, si hubiera vivido más años, «hoy día tendría España su poeta, y él solo compensaría abundantemente las faltas de otros muchos» (ibid.). Al siglo XVI, siglo de «muchos y excelentes poetas», sigue el desgraciado periodo ya evocado, y Luzán no duda en designar a los culpables: Lope y Góngora. Más exactamente censura al Lope dramaturgo, pero celebra el ingenio, la facilidad y otras muchas dotes naturales del poeta. En cambio, el juicio muy severo que emite sobre Góngora no deja paso a muchas concesiones:

Góngora, dotado de ingenio y de fantasía muy viva, pero desreglada, y ambicioso de gloria, pretendió conseguirla con la novedad del estilo, que en todas sus obras (excepto los romances 
y alguna otra composición, que no sé cómo se preservaron de la afectación de las otras) es sumamente hinchado, hueco y lleno de metáforas extravagantes, de equívocos, de antítesis y de una locución a mi parecer del todo nueva y extraña para nuestro idioma. (ibid.)

Procede esta cita del cápitulo tercero (libro I) de la Poética, que presenta no pocas modificaciones en la segunda edición de la obra. Se sabe que, probablemente por tomar en cuenta los reparos hechos a la primera edición, Luzán había decidido redactar una nueva versión con cambios y adiciones importantes. Cuando muere en 1754, parece ser que estaba casi terminada; pero, como solo se publicó en 1789, gracias a Eugenio de Llaguno que había ayudado a Luzán en la tarea, habiéndose perdido además el manuscrito, resulta en muchos casos imposible determinar a quién se deben las variantes. Con todo, no carecen de interés los cambios introducidos en la lista de excelentes poetas que se halla en dicho capítulo. En la edición de 1737, aparecen los cinco nombres ya mencionados; en la de 1789, llegan a más de treinta, si se incluyen a «los señores de distinguida nobleza» que cultivaban las musas y entre los cuales figura un bisabuelo de Luzán ${ }^{25}$. El sitio reservado a unos nobles poetas aragoneses no deja muchas dudas sobre la paternidad de dicha lista o, por lo menos, sobre la participación de Luzán a su elaboración. La adición de algunos nombres (en particular los de Ulloa, Lope, los Argensolas y Jáuregui) se justifica por las numerosas menciones elogiosas que de sus poemas se hacen en la Poética. Menos comprensible es la cantidad de los elegidos, en algunos casos según criterios algo dudosos, tanto más cuanto que la lista no es limitativa. Esta tendencia inflacionista lleva a pensar que lo que pretende Luzán no es entonces presentar un Parnaso, sino ostentar la riqueza de la poesía española en los siglos de Oro y, a la vez, enmendar la primera edición, tan mezquina en este punto.

Lo que resulta más extraño aún es la presencia de Góngora en esta lista, cuando en el mismo capítulo sigue denunciado como el mayor responsable

25. He aquí la lista: «Después de Boscán y Garcilaso florecieron en España excelentes poetas: Gutierre Cetina, Fernando de Herrera, Jerónimo Lomas de Cantoral, el maestro fray Luis de León, Luis Barahona de Soto, Juan de Malara, Felipe Mey, Vicente Espinel, don Alonso de Ercilla, Francisco de Figueroa, Pedro de Padilla, Lope de Vega, Miguel de Cervantes, Lupercio y Bartolomé Leonardo de Argensola, don Juan de Jáuregui, don Esteban Manuel de Villegas, don Francisco de Quevedo, Cristóbal Suárez de Figueroa, don Luis de Góngora, don Pedro Soto de Rojas, don Luis de Ulloa y otros muchos que sería largo nombrar, entre los cuales se numeran señores de distinguida nobleza, que a los timbres de sus casas ilustres no se desdeñaron de añadir los poéticos laureles, como el príncipe de Esquilache, el Almirante, el conde de la Roca, el conde de Villamediana, el conde de Rebolledo, y en Aragón el marqués de Sanfelices y don Baltasar López de Garrea, conde del Villar, debiéndose perdonar a mi natural amor y respeto la memoria que aquí hago de este bisabuelo mío.» (p. 143) 
de «la propagación y crédito del mal estilo». Es cierto que, en la segunda edición, se insiste en el hecho de que «en las letrillas, romances, y poesías satíricas y burlescas en versos cortos, apartándose de aquella sublimidad afectada y acercándose más a la naturalidad, escribió mejor con particular gracia y viveza» (p. 144). Así queda atenuada una crítica que, en el fondo, no cambia, como lo demuestra la permanencia de ataques virulentos contra otros poemas de Góngora. En las Soledades, Luzán censura la obscuridad de "tan enmarañadas cláusulas», y se vale con habilidad de los comentarios burlones de Quevedo y Jáuregui, acudiendo en otra parte a Cervantes o a Lope, para recordar que no siempre en España se ponderó la belleza del estilo culterano ${ }^{26}$. El no respeto de la regla de la «semejanza», regla también preconizada con insistencia por Mayans, es lo que provoca el más largo y acerbo comentario de la escritura gongorina en la Poética. El poema incriminado es un soneto ${ }^{27}$ en el cual apunta Luzán extravagantes translaciones, imágenes «monstruosas» que le costaron no pocas cavilaciones para llegar a una posible interpretación. Naturalmente no hay que ver una prueba de humildad en la confesión de tales dificultades de comprensión, sino la voluntad de subrayar el carácter impenetrable de esta poesía, opuesta a todos los criterios de la belleza poética. Piensa Luzán que así deja bien sentado que el título de "príncipe de los poetas líricos» otorgado a Góngora es usurpado, y justifica tan dilatado análisis de un poema, que podría tacharse de digresión, por «el celo justo de desarraigar tan mala hierba del Parnaso español» (p. 279).

Esta censura le valió una respuesta de uno de los redactores del Diario de los Literatos. En una reseña más bien favorable de la Poética, Juan de Iriarte le explica a Luzán el sentido de los versos para él tan oscuros y, sobre todo, le reprocha haberse ensańado con Góngora "sacando siempre sus versos para ejemplo de imperfecciones, y nunca para dechado de aciertos» ${ }^{28}$. Son páginas en las que se transparenta la dificultad que tiene Iriarte para admitir el valor absoluto de la preceptiva recordada en la Poética, así como el total rechazo del culteranismo, parte integrante de la historia literaria nacional. No se dio por vencido Luzán y contestó a los diaristas por medio del Discurso apologético de don Iñigo de Lanuza, seudónimo fácil de descifrar ${ }^{29}$, un discurso repleto de

26. Lib. II, cap. VII, éd. cit., p. 222.

27. Lib. II, cap. XIV, p. 277-279. El primer verso del soneto es: «Este que Babia al mundo hoy ha ofrecido».

28. Diario de los Literatos, t. IV, oct., nov., dic. de 1737, p. 100.

29. El Discurso apologético de don Íñigo de Lanuza, donde procura satisfacer los reparos de los Señores Diaristas sobre la Poética de don Ignacio de Luzán [1741] ha sido editado, con abundantes notas y comentarios, por Guillermo Carnero: Ignacio de Luzán, Obras raras 
referencias eruditas para dar más peso a los argumentos esgrimidos. Admite una comprensión errónea de algunos versos del soneto y, también, unos excesos en la formulación de los reproches. Sobre el fondo, en cambio, no cede nada: «De Góngora me parece que censura poco el señor Luzán para desengaño de los muchos que, no entendiendo lo que dice, idolatran sus enigmas, y de otros que gustan desenmarañar sus confusiones» (éd. cit., p. 96). En esta categoría entraba naturalmente Juan de Iriarte. «Tedio» es lo que siente ante una poesía en la que solo encuentra "oscuridad y artificio», totalmente contrarios a «la naturalidad y facilidad aparente» que caracterizan los bellos versos. No piensa, por lo tanto, abandonar la lucha contra «el espíritu poético de Góngora, sea espíritu bueno o malo», y reafirma el fin de su combate: conseguir que «la elocuencia y la poesía española se vean algún día libres de su tiranía y restituidas a su antiguo lustre y esplendor» (p. 140). Huelga decir que nunca entraría Góngora en el Parnaso de Luzán. Mucho más ecuánime y moderado se muestra siempre Mayans con aquel poeta, a quien distingue de sus menos inspirados continuadores.

Tan detenida exposición de la repugnancia que le inspira a Luzán la poesía lírica de Góngora parecerá excesiva, pero corresponde a la importancia que cobra en los primeros libros de la Poética la lucha contra los poetas culteranos, siendo el jefe de la tropa el primer apuntado. A los contraejemplos que son Góngora, Silveira o Luis Martín de la Plaza, opone Luzán varios modelos. Entre ellos sobresale Garcilaso, cuyas églogas y canciones están citadas dos veces más que los poemas de Lupercio Leonardo Argensola, que ocupa el segundo puesto en el Parnaso español de Luzán, y no solo porque es un compatriota suyo ${ }^{30}$. Vienen luego Ulloa, alabado en particular por haberse librado del contagio barroco, y Jáuregui, «poeta de singular mérito». Muy apreciados también, aunque menos citados (entre una y tres veces) son: Fr. Luis de León, Villegas, Francisco de Borja, Solís, Juan del Encina, Manrique, Boscán, López de Zárate, Cristóbal de Castillejo y Juan de Mal Lara. Lope de Vega constituye un caso aparte, dado que está nombrado tanto para ser alabado como reprendido. Le reprocha sobre todo Luzán, pero sin acrimonia, haberse excedido en unos juegos metafóricos incoherentes; en cambio, le parece excelente en el estilo jocoso, cultivado también con éxito por Quevedo y Gerardo Lobo. Confirma además, en el Discurso apologético,

y desconocidas, vol. II, Zaragoza, Univ. de Alicante - Institución «Fernando el Católico», 2003.

30. Al explicar la manera de crear imágenes simples y naturales, Luzán escoge el ejemplo de Argensola a quien introduce de este modo: «Y, comenzando por Lupercio Leonardo de Argensola, para que me deba aquí como compatriota el primer lugar, que ya por tantos títulos merece $[\ldots] »$, p. 250. 
que no pone en el mismo plano al poeta Lope de Vega y a Góngora, «ocupando el primero sin disputa [...] uno de los mejores lugares en nuestro Parnaso» (p. 96).

Más que por los poetas españoles seleccionados, se diferencia Luzán de Mayans por el sitio privilegiado que reserva, en su Parnaso, a grandes poetas de la Antigüedad (primero a Virgilio, y luego a Ovidio, Catulo, Horacio, Tibulo, Marcial, Homero), citados las más veces en latín. En la medida en que Luzán quiere demostrar que los preceptos rememorados en su tratado son intemporales, se muestra perfectamente coherente cuando yuxtapone poetas antiguos y modernos. Aún más notable es la presencia, entre los modelos, de dos jesuitas: el francés René Rapin y sobre todo el italiano Tomasso Ceva, cuyos poemas (naturalmente escritos en latín) cita, por lo menos, tantas veces como los de Ulloa. Mayans, que fue alumno de los jesuitas como Luzán, tiene una actitud muy distinta al respecto, cuando resuelve acabar con las referencias obligadas a ejemplos grecolatinos en su Rhetórica. Puesto que se trataba para él de proponer a los espańoles modelos de escritura y de aficionarles a la literatura nacional, no podía ser otra su decisión.

Siempre dentro de la lógica que le lleva a Luzán a pensar que pueden encontrarse en los mejores poetas de cualquier nación civilizada ilustraciones de sus admirados preceptos, propone también en la Poética varios ejemplos en lengua portuguesa de dos poetas del siglo XVI: uno de Diego Bernardes y muchos más de Camóes. Como era de esperar, Luzán no olvida a Italia, representada por Petrarca, el Tasso y Chiabrera, siempre en lengua original. Se confirma esta especificidad en la edición de 1789, con la inclusión de unos extractos del Paraíso perdido de Milton, traducidos al castellano para ser más asequibles a los lectores españoles.

Se observa también que, en la Poética, la teoría está más desarrollada que en la Rethórica, y los ejemplos citados para apoyar la demostración son menos numerosos y mucho más breves. En cambio Luzán, a quien le gustaba el ejercicio de la poesía, comenta mejor que Mayans los textos aducidos y procura indicar en qué consisten los aciertos (o desaciertos) de los versos citados. Sirvan de muestra las explicaciones que da a propósito de un soneto de Garcilaso, elegido como dechado de una perfecta comparación:

Quería Garcilaso declarar el error y engaño de su razón, que concedía a su pensamiento un objeto tan deseado como dañoso. Discurriendo, pues, su ingenio por todos los entes, halló luego, entre ellos, uno, cuya semejanza hacía más claro el objeto que una larga descripción; vio que sucedía lo mismo a su razón que a una madre cuando, vencida al llanto de un hijo enfermo, le concede alguna cosa de la cual, comiendo, se le acrecienta el mal. Con esta comparación, 
tan bella, como tierna, logró él explicar claramente lo que quería decir, y al msimo tiempo adornó de incomparable belleza este soneto [cita el soneto: Como la tierna madre que el doliente / hijo...]

Más adelante intenta mostrar cómo se ajusta dicha comparación a la norma que acaba de recordar:

Así en la comparación de Garcilaso, uno y otro objeto concuerdan admirablemente en el punto principal: el hijo y el pensamiento, entrambos enfermos, piden a la madre y a la razón una cosa respectivamente dańosa a uno y a otro, y la madre y la razón se les conceden, aunque conocen el daño que se les ha de causar. Este es el punto principal que se pretende explicar, y en éste convienen perfectamente la comparación y el objeto comparado. (p. 291)

No sé si por aquellas fechas se podía ir más lejos en el análisis de un texto literario.

Como buen partidario del enseñar deleitando, recuerda Luzán que la poesía, lo mismo que las demás formas literarias, tiene una «utilidad», es decir una función ética. Cumple la sátira esta misión denunciando a los vicios. Del mismo modo, "todas las composiciones líricas que contienen alabanzas de las virtudes y de las acciones gloriosas son utilísimas por los buenos efectos que causan en quien las lee» (p. 194). Dañosos, al contrario, son los poetas «lascivos» por tratar de asuntos deshonestos, y hay que apartarlos inexorablemente del Parnaso:

Semejantes poetas, aunque en lo demás hubieran llegado a la perfección, ya desmerecieron por defecto tan notable el nombre de buenos poetas; mas de estos tales no hablo ni hallo razón para defenderlos, mayormente estando, a Dios gracias, nuestros poetas exentos de tal nota, pues no se leen en sus obras, que yo sepa, como en algunas de otras naciones aquellos asuntos tan opuestos a la modestia y recato de las buenas Musas [...]. (ibid.)

Por una vez, nada tenía que envidiar la poesía española a las demás naciones.

España, justamente, está en el centro de la Poética y de la Rhetórica, pero de distinta manera. Tanto Luzán como Mayans quieren reformar la elocuencia y la poesía espańolas, y lo intentan por vías que pueden cruzarse, pero no se confunden. Luzán llega a España con una doctrina heredada de los Antiguos, pero revisada por teóricos modernos. La doxa que quiere imponer a sus compatriotas, en realidad, procede de fuera y representa para él una manera de acercar su patria a Europa. Una actitud militante con exceso lo lleva a practicar exclusiones que parecen dictadas por fobias 
personales más que por motivos literarios. Mayans, en cambio, como lo ha afirmado con razón François Lopez en varios estudios, no es neoclásico ${ }^{31}$. Es un humanista que se sitúa en la corriente iniciada en el siglo XVI por un Vives (cuando protestaba contra los vicios que afeaban el lenguaje castellano), corriente que prosigue en el siglo XVII (con unos tratadistas como Pedro de Valencia) coexistiendo con el llamado barroco, y se reafirma con Nicolás Antonio y el deán Martí. En el siglo XVIII, Mayans toma el relevo y, aunque no ignora lo que se escribe en Europa acerca de la literatura española, cree en la posibilidad de reformarla desde dentro, entroncando con dicha corriente nacional y practicando una sana, pero justa, crítica. Y así, cuando Luzán procura reformar el gusto de sus compatriotas acercándolo a un patrón europeo, Mayans prefiere una formación por medio de modelos exclusivamente españoles, seleccionados con esmero. Más que por el fin perseguido, se diferencian los dos literatos por la manera de conseguirlo, y es un fenómeno que puede observarse a lo largo del siglo de la Luces fuera del ámbito literario.

No divergen en todo Mayans y Luzán. Comparten, en particular, el respeto por la preceptiva clásica, la fe en la imitación de modelos escogidos que uno ha de apropiarse antes de dar más libertad a su ingenio. Tampoco difiere su visión de la historia de la poesía española, de sus periodos de auge y de decadencia. Si se comparan sus respectivos Parnasos, a pesar de ser el de Luzán mucho más ecléctico que el de Mayans, se encuentran más o menos los mismos nombres y se observa en ambos una marcada preferencia por los poetas castellanos del siglo XVI. Por fin les reúne una notable influencia en el mundo de las letras dieciochesco. Aunque tarda en manifestarse, la de Luzán es indiscutible en la evolución del teatro y de la poesía, por reacción a la escritura barroca. A la de Mayans, menos ruidosa, se debe en gran parte la elaboración, en la segunda mitad del siglo XVIII, de numerosas antologías de prosistas y poetas y, también, la publicación de muchos escritores del siglo XVI que no se habían editado desde hacía más de cien años. No es exagerado afirmar que hubiera sido muy distinta la vida literaria dieciochesca sin la presencia activa de aquellas dos figuras, a la vez cercanas y lejanas.

31. Además del estudio citado sobre «Mayans y sus poetas», véanse «La institución de los géneros literarios en la Espańa del siglo XVIII», Bulletin Hispanique, 102, 2000, n 2, p. 473-517, y "Sobre los géneros y otros conceptos de la crítica en la España moderna», Bulletin Hispanique, $\mathrm{n}^{\circ}$ 1, juin 2004 («Penser la littérature espagnole»), p. 317-350. 